\title{
Dietary fat guidelines have no evidence base: where next for public health nutritional advice?
}

\author{
Zoë Harcombe
}

Correspondence to Dr Zoë Harcombe, Institute of Clinical Exercise and Health Science, University of the West of Scotland, Almada Street, Hamilton ML3 0JB, UK; zoe@ theobesityepidemic.org

Accepted 25 September 2016 Published Online First 18 October 2016

\author{
ABSTRACT \\ Introduction National dietary guidelines were \\ introduced in 1977 and 1983, by the US and UK \\ governments, with the aim of reducing coronary heart \\ disease (CHD) mortality. The 2 specific dietary fat \\ recommendations were to reduce total fat and saturated \\ fat consumption to $30 \%$ and $10 \%$ of total energy \\ intake, respectively.
}

Methods 4 systematic reviews (3 with meta-analysis) were undertaken to examine the evidence for these dietary fat guidelines: (1) randomised controlled trial $(\mathrm{RCT})$ and (2) prospective cohort (PC) evidence at the time the guidelines were introduced; and (3) RCT and (4) PC evidence currently available. This narrative review examines all evidence collated.

Results The RCT and PC evidence available to the dietary committees did not support the introduction of the dietary fat guidelines. The RCT and PC evidence currently available does not support the extant recommendations. Furthermore, the quality of the evidence is so poor that it could not be relied on had it provided support.

Conclusions Dietary fat guidelines have prevailed for almost 40 years. The evidence base at the time of their introduction has been examined for the first time and found lacking. Evidence currently available provides no additional support. Public health opinion differed when the guidelines were introduced. Opposition to the guidelines is becoming more strident. Substantial increases in diet-related illness over the past four decades, particularly obesity and type 2 diabetes, indicate that a review of dietary advice is warranted.

\begin{abstract}
"The urgency of finding means of prevention is sharpest for men in middle age for it is in that group that the social cost of CHD is greatest... Starting with men aged 40 through 59, the follow-up would show CHD causing close to $40 \%$ of all deaths in five years. It is understandable, then, that most work on the epidemiology of CHD begins with men of those ages. Ancel Keys, The Seven Countries Study (1970) (ref 1, p. I-1).”
\end{abstract}

\section{INTRODUCTION}

The first part of the diet-heart hypothesis, that serum cholesterol was related to coronary heart disease (CHD), originated from the work of Russian pathologists in the early 20th century. Having observed fatty deposits in arteries during postmortems, a number of researchers sought to understand if dietary cholesterol determined serum cholesterol. $^{2-9}$ The summary of findings from the original animal studies was that: rabbits (herbivores) fed animal foods developed fatty deposits/ changes in the aortas; rats (omnivores) fed animal foods produced no observable changes in the aortas; and rabbits fed cholesterol in plant food showed no arterial damage.

In the 1950s, Keys undertook several experiments with human subjects and concluded "that the cholesterol content, per se, of all natural diets has no significant effect on either the serum cholesterol level or the development of atherosclerosis in man" (ref. 10, p. 182).

The logic that only animal foods contain cholesterol and thus, if animal foods consumed to administer dietary cholesterol had no impact on serum cholesterol then animal foods per se had no impact on serum cholesterol was overlooked. Attention turned to dietary fat in food when non-animal foods would have been more logical to examine.

The second part of the diet-heart hypothesis, that dietary fat and serum cholesterol were related, followed observational studies of men in Minnesota, Naples, Slough and Madrid. Keys et $a l^{11}$ concluded that the total fat content of the diet (as a proportion of calories) exerted a powerful influence on the serum cholesterol level in man. Age appeared to be a confounder, with cholesterol rising to the age of 50-55 in Minnesotan and Slough men and rich men in Madrid. Neopolitan men and poor men in Madrid demonstrated stable and falling cholesterol levels, respectively, between the ages of 40 and 50, rising before these ages.

The third part of the diet-heart hypothesis, that dietary fat and CHD were related, was first presented with the graph of deaths from heart disease and calories from total fat in men aged 55-59, for six countries, from the Mount Sinai presentation of 1953. ${ }^{12}$ The response of Yerushalmy and Hilleboe $^{13}$ demonstrated that data were available for 22 countries.

Keys et $a l^{10}$ concluded that no other variable, besides the fat calories in the diet, showed anything like such a consistent relationship to the mortality rate from $\mathrm{CHD}$.

The first statement of the diet-heart hypothesis, with the three component parts, appears to have been made in a 1955 publication, which explored the relationship between dietary fat, serum cholesterol and CHD in different ethnic groups in Cape Town. ${ }^{14}$ This paper confirmed that total fat intake and animal fat intake were the subjects of examination. Saturated fat was not mentioned.

This was the context for the start of the Seven Countries Study in 1956-1958. The Seven Countries Study concluded that there was no relationship with total fat and CHD, but that there was a strong correlation between saturated fat intake and CHD in cross country comparison. ${ }^{1}$ 
In ideal research circumstances, epidemiological evidence would have established clear and consistent associations and then well designed randomised controlled trials (RCTs) would have followed epidemiological findings and set out to test associations found. This did not happen with the development of the diet-heart hypothesis. Possibly the sense of urgency took over. The epidemiology and RCTs were running in parallel from the 1950 s onwards.

The focus on men, and men who had already had a heart attack in the case of the RCTs, was understandable in the context of the Keys' quotation opening this paper. This focus, however, lacked generalisability for the population as a whole.

\section{METHODS}

Four systematic reviews and, where possible, meta-analysis were undertaken to examine the evidence base for dietary fat guidelines. The first review examined RCT evidence available to the dietary guideline committees in 1977 and $1983 .{ }^{15}$ The second review examined epidemiological evidence available to the dietary guideline committees. ${ }^{16}$ The third review examined RCT evidence available today, to see if extant dietary guidelines have been proven in retrospect. ${ }^{17}$ The fourth review examined epidemiological evidence available today, to see if extant dietary guidelines have been proven in retrospect. ${ }^{18}$

This paper summarises the findings of the four reviews undertaken, to consider all evidence available at the time of the introduction of dietary guidelines and that currently available, to assess the evidence base for dietary advice. It summarises the conclusions of other meta-analyses of RCTs and/or prospective cohort studies, highlighting the predominance of non-significant findings. It discusses population health trends since the introduced dietary guidelines, and considers if a simple public health message could offer a way forward.

\section{RESULTS}

\section{The findings}

Public health advice for all citizens should be informed by conclusive, consistent evidence from numerous robust studies of an appropriate representative group of such citizens (large enough, long enough, studies of healthy men and women of all ages). This did not happen before the guidelines were set. It has not happened since and it is unlikely to happen in the future, considering cost, ethical and confounding variable complications, such as the prevalence of medication. There are two key issues with the evidence in the four systematic reviews. ${ }^{15-18}$

\section{The conclusions of the evidence}

The evidence available to the dietary committees at the time the guidelines were introduced did not support the recommendations made. A systematic review and meta-analysis of RCTs available in 1977/1983, where a dietary fat intervention had been made, revealed identical all-cause mortality (30\% in intervention and control groups) and no statistically significant difference in deaths from CHD. ${ }^{15}$ A systematic review of prospective cohort studies available in 1977/1983 found one study, the Seven Countries Study, offering support for saturated, but not total, fat to be a subject for further examination and five studies with no significant findings in relation to total, or saturated, dietary fat. ${ }^{16}$

The evidence currently available offers no additional support. A systematic review and meta-analysis of dietary fat RCTs currently available, where a dietary fat intervention had been made, found no statistically significant difference in all-cause mortality or deaths from $\mathrm{CHD} .{ }^{17} \mathrm{~A}$ systematic review and meta-analysis of prospective cohort studies currently available found no statistically significant results to implicate total or saturated fat in CHD mortality. ${ }^{18}$

With one exception, the specific guidelines of $30 \%$ total fat and $10 \%$ saturated fat have not been tested. The St Thomas' Atherosclerosis Regression Study (STARS) ${ }^{19}$ was the only study to examine targets approximating to those set by dietary guidelines, with a total fat consumption of $27 \%$ and an $8-10 \%$ saturated fat intake. The Diet and Reinfarction Trial (DART) ${ }^{20}$ tested a $30 \%$ total fat diet, although this was not a controlled variable, as the intervention also tried to achieve a 1:1 polyunsaturated to saturated fat ratio. Two RCTs studied an approximate 20\% fat diet: the 1965 Research Committee Low-fat Diet; and the Women's Health Initiative (2006). ${ }^{21} 22$ Woodhill et $a l^{23}$ and Frantz et $a l^{24}$ reviewed the consequence of a $10 \%$ saturated fat diet, without the total fat dietary guideline restriction. The prospective cohort studies examined grams of fat intake for those who died from CHD versus those who did not, or fat intake as a percentage of calories, sometimes in absolute amounts, sometimes comparing lowest and highest tertiles, quartiles or quintiles. They did not examine populations for outcomes related to the two dietary fat guidelines. This is not a criticism of the studies. Public health policy should follow evidence, not the other way round.

The STARS RCT claimed that its findings supported the use of a lipid-lowering diet in men with CHD. ${ }^{19}$ Three prospective cohort studies reported strong evidence for an association between dietary fat and CHD: the Seven Countries Study found an association with saturated fat; ${ }^{25}$ Boniface and $\mathrm{Tefft}^{26}$ found an association with both total and saturated fat, but for men only, not women; $\mathrm{Xu}$ et $a l^{27}$ found associations for total fat, saturated fatty acid and monounsaturated fatty acid intake in American Indians aged 47-59 years, but not older.

All other RCTs and prospective cohort studies reported no significant findings for total or saturated dietary fat: four RCTs issued cautions about the safety and/or efficacy of their interventions. $^{21} 232829$ Rose et al ${ }^{28}$ reported that corn oil was most unlikely to be beneficial, and was possibly harmful. The Research Committee Low-fat Diet concluded that a low-fat diet has no place in the treatment of myocardial infarction. ${ }^{21}$ Dayton et $a l^{29}$ noted the absence of any benefit for longevity and expressed concern about toxicity of the intervention. Woodhill et $a l^{23}$ reported that survival was significantly better in the control than the diet group.

Regarding the serum cholesterol part of the diet-heart hypothesis, the RCTs at the time and currently available collectively reported greater reductions in mean serum cholesterol levels in the intervention groups, but this did not result in a reduction in deaths, from $\mathrm{CHD}$ or all causes. These findings raise questions about the mechanism of cholesterol-lowering medications, such as statins. It has been assumed that statins lower cholesterol and lowering cholesterol lowers death rates. There may be another mechanism by which statins have an effect, independent of cholesterol. Caution should be adopted in using cholesterol as a surrogate end point: the new proprotein convertase subtilisin/kexin type 9 inhibitors (PCSK9) are being launched with surrogate end point evidence alone, without evidence for CHD mortality. ${ }^{30}$

Plant sterols offer a plausible explanation for dietary interventions lowering cholesterol, but not mortality. Phytosterols are cholesterol-like molecules found in all plant foods, with the highest concentrations occurring in vegetable oils. They are absorbed only in trace amounts, but inhibit the absorption of intestinal cholesterol. ${ }^{31}$ The most commonly occurring 
phytosterols in the human diet are $\beta$-sitosterol, campesterol and stigmasterol, which account for $\sim 65 \%, 30 \%$ and $3 \%$ of diet contents, respectively. ${ }^{32}$ The ability of phytosterols to inhibit the absorption of cholesterol was first established in $1953 .{ }^{33}$ However, there is no evidence that plant sterols reduce the risk of $\mathrm{CHD}$ and much evidence that they are detrimental. ${ }^{34}$

\section{The quality of the evidence}

Even if the evidence from prospective cohort studies and RCTs had been overwhelming, the limitations of the studies were so great that the evidence could not be relied on. Only one RCT was a primary prevention study of men and women. ${ }^{24}$ Only one prospective cohort study, with evidence for CHD mortality, examined men and women, free from CHD at the baseline. ${ }^{35}$ All prospective cohort studies suffered the limitations of dietary questionnaires. ${ }^{36-40}$ Other limitations of each study have been documented in the systematic reviews. ${ }^{15-18}$

\section{The Seven Countries Study}

The strongest evidence presented, among 10 RCTs and 13 prospective cohort studies, came from the Seven Countries Study (1970). ${ }^{25}$ Keys noted in the introduction to the Seven Countries Study publication that association did not mean causation, but the strength of conclusions did not adopt this caution. The conclusions of this study defined the diet-heart hypothesis as the tripartite association of saturated fat, serum cholesterol levels and CHD, the impact of dietary cholesterol and total dietary fat having been rejected. ${ }^{25}$

The correlations established by the Seven Countries Study were strong. The correlation between median serum cholesterol level and CHD deaths and infarctions (data for CHD deaths alone were not presented) per 100 people was $r=0.76$ $(p<0.05)$. The correlation between CHD deaths and infarctions and saturated fat as a percentage of calories was $r=0.84$ $(p<0.05) .{ }^{41}$ However, these correlations were for countries versus each other, not for people in one country who died from $\mathrm{CHD}$ versus those in the same country who did not.

The confounders were significant, including, but not limited to: geography, lifestyle, gross domestic product, climate, politics, other aspects of national diet, national health provision, etc. When asked about the value of Keys' work, a contemporary of the time, Professor Peter Elwood, described intercountry studies as 'the lowest form of evidence' (P Elwood, personal communication, 2015).

The Seven Countries Study suffered from further limitations with the preselection of countries known to be associated: an average of $3.4 \%$ of men sampled for dietary information; and the inclusion of men with pre-existing CHD, with the finding that the CHD death rate within 5 years was $20.9 \%$ for secondary males and $1.0 \%$ for primary males.

Without these limitations, the strong correlations established by the Seven Countries Study were not unique. Equally strong correlations had been established with animal protein, with gross domestic product suggested as the confounder ${ }^{13}$ and television sets and vehicle licenses. ${ }^{42}$ The strongest correlation was established with latitude: the correlation coefficient for CHD deaths and the latitude of the 16 cohorts in the Seven Countries Study was 0.93; the correlation coefficient for CHD deaths and the latitude of the seven countries was $0.96 .^{16}$

A definitive assessment of the strength of associations found in research was proposed by Bradford Hill with his nine criteria. ${ }^{43}$ In 2009, Mente et al reviewed RCTs and prospective cohort studies against these criteria for numerous foods and nutrients. They concluded: "Insufficient evidence of association is present for intake of ... saturated and polyunsaturated fatty acids; total fat; linolenic acid; meat; eggs and milk" (ref. 44, p. 659).

Although the Seven Countries Study was not referenced by the US committee February publication, ${ }^{45}$ it was referenced by the UK committee ${ }^{46}$ and Keys and his research was referenced 40 times in the 869 supplemental pages to the dietary guidelines. ${ }^{47}$ The fact that Keys had appeared on the front cover of Time Magazine attested to the regard with which he was held. ${ }^{48}$ There can be little doubt that the Seven Countries Study had a significant impact on the introduction of dietary fat guidelines.

\section{Other meta-analyses}

A number of meta-analyses of RCTs, examining dietary fat and mortality have been undertaken by other authors. ${ }^{49-51}$ One meta-analysis of prospective cohort studies has been undertaken by other authors, Siri-Tarino et al. ${ }^{52}$ Two additional meta-analyses reviewed both RCTs and prospective cohort studies: ${ }^{53}{ }^{54}$ Skeaff and Miller (2009) sought to summarise the evidence from cohort studies and RCTs of the relation between dietary fat and risk of CHD. Their conclusion was "Intake of total fat was not significantly associated with CHD mortality. Intake of total fat was also unrelated to CHD events" (ref. 53, p. 175). Chowdhury et al (2014) set out to summarise evidence between fatty acids and coronary disease. Their review examined saturated, monounsaturated, polyunsaturated and trans fats, while also reviewing individual chain length fatty acids, palmitic (C16:0) and margaric (C17:0) as examples. The conclusion was "Current evidence does not clearly support cardiovascular guidelines that encourage high consumption of polyunsaturated fatty acids and low consumption of total saturated fats" (ref. 54, p. 398).

Table 1 summarises the findings from other meta-analyses of RCTs and/or prospective cohort studies. There were 39 reports of risk ratios (RRs) from meta-analysis with $95 \%$ CIs. Of these, 4 reported significant findings; 35 reported no significant findings. One of the significant findings, from Chowdhury et al, ${ }^{54}$ related to trans fats, not total or saturated fat. It found that trans fat intake was positively associated with coronary disease. Another of the significant findings came from the Mozaffarian $e t a l^{51}$ study of the impact of replacing saturated fat with polyunsaturated fat, which was criticised ${ }^{56}$ for excluding two studies that would have moderated this conclusion ${ }^{23} 28$ and including a favourable, but non-randomised crossover, trial excluded by all other meta-analyses. ${ }^{57}$

The other two significant findings were related to cardiovascular disease (CVD) events and not mortality. ${ }^{50} 55$ In 2011, including RCTs with a minimum of 6 months duration, Hooper et al found 1 significant result and 11 non-significant results. The one significant result was that, when all RCTs were examined together, the RR for CVD events from meta-analysis was 0.86 (95\% CI 0.77 to 0.96 ). In 2015, including RCTs with a minimum of 24 months duration, Hooper et al found one significant result and seven non-significant results. The one significant result was, when a reduction in saturated fat was examined, the RR for CVD events from meta-analysis was 0.83 (95\% CI 0.72 to 0.96 ).

As a result of this 2015 review, Hooper et $a l^{55}$ suggested that there may be a small reduction in cardiovascular risk with reduction of saturated fat intake. It was further suggested that replacing the energy from saturated fat with polyunsaturated fat "appears to be a useful strategy, and replacement with carbohydrate appears less useful" (ref. 55, p. 2) and replacement with monounsaturated fat unclear. Of the 11 interventions contributing to this conclusion, only 1 documented both saturated fat 
Table 1 Summary of meta-analyses of RCTs and prospective cohort studies

\begin{tabular}{|c|c|c|c|c|c|c|c|}
\hline & Studies examined & Studies & People & Measure & Fat & Risk ratio & Conclusion \\
\hline $\begin{array}{l}\text { Skeaff and Miller } \\
(2009)^{53}\end{array}$ & $\begin{array}{l}\text { Prospective cohort } \\
\text { studies and RCTs }\end{array}$ & 28 & 280000 & $\begin{array}{l}\text { CHD mortality } \\
\text { CHD events }\end{array}$ & $\begin{array}{l}\text { Total fat } \\
\text { Total fat }\end{array}$ & $\begin{array}{l}0.94(0.74 \text { to } 1.18) \\
0.93(0.84 \text { to } 1.03)\end{array}$ & $\begin{array}{l}\text { No significant difference } \\
\text { No significant difference }\end{array}$ \\
\hline $\begin{array}{l}\text { Siri-Tarino et al } \\
(2010)^{52}\end{array}$ & $\begin{array}{l}\text { Prospective cohort } \\
\text { studies }\end{array}$ & 21 & 347747 & $\begin{array}{l}\text { CHD fatal and non-fatal } \\
\text { CVD fatal and non-fatal }\end{array}$ & $\begin{array}{l}\text { Saturated fat (extreme } \\
\text { quintiles) } \\
\text { Saturated fat (extreme } \\
\text { quintiles) }\end{array}$ & $\begin{array}{l}1.07(0.96 \text { to } 1.19) \\
1.00(0.89 \text { to } 1.11)\end{array}$ & $\begin{array}{l}\text { No significant difference } \\
\text { No significant difference }\end{array}$ \\
\hline $\begin{array}{l}\text { Mozaffarian et al } \\
(2010)^{51}\end{array}$ & RCTs & 8 & 13614 & CHD events & Replacing SFA with PUFA & 0.81 (0.70 to 0.95$)$ & Significant difference \\
\hline $\begin{array}{l}\text { Hooper et al } \\
(2011)^{50}\end{array}$ & RCTs & 21 & 71790 & $\begin{array}{l}\text { CVD mortality } \\
\text { CVD events }\end{array}$ & $\begin{array}{l}\text { All RCTs } \\
\text { Modified fat } \\
\text { Reduced fat } \\
\text { Reduced and modified fat } \\
\text { All RCTs } \\
\text { Modified fat } \\
\text { Reduced fat } \\
\text { Reduced and modified fat } \\
\text { All RCTs } \\
\text { Modified fat } \\
\text { Reduced fat } \\
\text { Reduced and modified fat }\end{array}$ & $\begin{array}{l}0.98 \text { (0.93 to } 1.04) \\
1.02(0.88 \text { to } 1.18) \\
0.97(0.90 \text { to } 1.04) \\
0.97(0.76 \text { to } 1.23) \\
0.94(0.85 \text { to } 1.04) \\
0.92 \text { (0.73 to } 1.15) \\
0.96 \text { (0.82 to } 1.13) \\
0.98 \text { (0.76 to } 1.27) \\
0.86 \text { (0.77 to } 0.96) \\
0.82(0.66 \text { to } 1.02) \\
0.97(0.87 \text { to } 1.08) \\
0.77(0.57 \text { to } 1.03)\end{array}$ & $\begin{array}{l}\text { No significant difference } \\
\text { No significant difference } \\
\text { No significant difference } \\
\text { No significant difference } \\
\text { No significant difference } \\
\text { No significant difference } \\
\text { No significant difference } \\
\text { No significant difference } \\
\text { Significant difference } \\
\text { No significant difference } \\
\text { No significant difference } \\
\text { No significant difference }\end{array}$ \\
\hline $\begin{array}{l}\text { Chowdhury et al } \\
(2014)^{54}\end{array}$ & $\begin{array}{l}\text { Prospective cohort } \\
\text { studies and RCTs }\end{array}$ & 32 & 530525 & $\begin{array}{l}\text { Coronary disease (All top } \\
\text { vs bottom third) }\end{array}$ & $\begin{array}{l}\text { Saturated fat } \\
\text { Monounsaturated fat } \\
\text { Polyunsaturated fat } \\
\text { Trans fat }\end{array}$ & $\begin{array}{l}1.02 \text { (0.97 to } 1.07) \\
0.99 \text { (0.89 to } 1.09) \\
0.93(0.84 \text { to } 1.02) \\
1.16(1.06 \text { to } 1.27)\end{array}$ & $\begin{array}{l}\text { No significant difference } \\
\text { No significant difference } \\
\text { No significant difference } \\
\text { Significant difference }\end{array}$ \\
\hline $\begin{array}{l}\text { Schwingshackl } \\
\text { and Hoffman } \\
(2014)^{49}\end{array}$ & RCTs & 12 & 7150 & $\begin{array}{l}\text { All-cause mortality } \\
\text { CVD mortality } \\
\text { CVD events } \\
\text { Mls } \\
\text { All-cause mortality } \\
\text { CVD mortality } \\
\text { CVD events } \\
\text { Mls }\end{array}$ & $\begin{array}{l}\text { Modified fat intake } \\
\text { Modified fat intake } \\
\text { Modified fat intake } \\
\text { Modified fat intake } \\
\text { Reduced fat intake } \\
\text { Reduced fat intake } \\
\text { Reduced fat intake } \\
\text { Reduced fat intake }\end{array}$ & $\begin{array}{l}0.92 \text { (0.68 to } 1.25) \\
0.96(0.65 \text { to } 1.42) \\
0.85(0.63 \text { to } 1.15) \\
0.76(0.54 \text { to } 1.09) \\
0.79(0.42 \text { to } 1.48) \\
0.93(0.66 \text { to } 1.31) \\
0.93(0.65 \text { to } 1.34) \\
1.18(0.88 \text { to } 1.59)\end{array}$ & $\begin{array}{l}\text { No significant difference } \\
\text { No significant difference } \\
\text { No significant difference } \\
\text { No significant difference } \\
\text { No significant difference } \\
\text { No significant difference } \\
\text { No significant difference } \\
\text { No significant difference }\end{array}$ \\
\hline $\begin{array}{l}\text { Harcombe et al } \\
(2015)^{15}\end{array}$ & RCTs to $1977 / 1983$ & 6 & 2467 & $\begin{array}{l}\text { All-cause mortality } \\
\text { CHD mortality }\end{array}$ & $\begin{array}{l}\text { Reduced or modified fat } \\
\text { Reduced or modified fat }\end{array}$ & $\begin{array}{l}0.99(0.87 \text { to } 1.15) \\
0.99(0.78 \text { to } 1.25)\end{array}$ & $\begin{array}{l}\text { No significant difference } \\
\text { No significant difference }\end{array}$ \\
\hline $\begin{array}{l}\text { Hooper et al } \\
(2015)^{55}\end{array}$ & RCTs & 12 & 55858 & $\begin{array}{l}\text { Total mortality } \\
\text { CHD mortality } \\
\text { CVD events } \\
\text { Mls } \\
\text { Non-fatal Mls } \\
\text { Stroke } \\
\text { CHD mortality } \\
\text { CHD events }\end{array}$ & $\begin{array}{l}\text { Reduced saturated fat } \\
\text { Reduced saturated fat } \\
\text { Reduced saturated fat } \\
\text { Reduced saturated fat } \\
\text { Reduced saturated fat } \\
\text { Reduced saturated fat } \\
\text { Reduced saturated fat } \\
\text { Reduced saturated fat }\end{array}$ & $\begin{array}{l}0.97(0.90 \text { to } 1.05) \\
0.95(0.80 \text { to } 1.12) \\
0.83(0.72 \text { to } 0.96) \\
0.90(0.80 \text { to } 1.01) \\
0.95(0.80 \text { to } 1.13) \\
1.00(0.89 \text { to } 1.12) \\
0.98(0.84 \text { to } 1.15) \\
0.87(0.74 \text { to } 1.03)\end{array}$ & $\begin{array}{l}\text { No significant difference } \\
\text { No significant difference } \\
\text { Significant difference } \\
\text { No significant difference } \\
\text { No significant difference } \\
\text { No significant difference } \\
\text { No significant difference } \\
\text { No significant difference }\end{array}$ \\
\hline
\end{tabular}

All studies examined data available at the time of the meta-analysis other than Harcombe et al, which examined data available to the dietary committees.

CHD, coronary heart disease; CVD, cardiovascular disease; Mls, myocardial infarctions; PUFA, polyunsaturated fatty acids; RCT, randomised controlled trial; SFA, saturated fatty acids.

reduction and reported that this was mainly replaced with polyunsaturated fat. ${ }^{29}$

It is important to differentiate between polyunsaturated fats. The DART provided early evidence for the benefit of omega-3 polyunsaturated fat, naturally abundant in fish. ${ }^{20}$ The only significant finding from this RCT was that all-cause mortality was lower for those following the fish advice, which was to increase fatty fish intake to at least two portions (200-400 g) weekly. The relative risk for fish advice versus no fish advice was 0.71 $(0.54-0.92)(p<0.05)$ (table IV, ref. 20, p. 759). This significant finding was explored further by the research team, but not found to be replicated. ${ }^{58}$ Omega- 6 polyunsaturated fats have proinflammatory properties, which can be mitigated by omega- 3 intake, ${ }^{59}$ but any dietary advice on polyunsaturated fats needs to be specific and evidence based.

The Hooper meta-analyses of 2011 and 2015 included four small studies (646 people in total), not included in any other meta-analysis, which were primarily studies of: diabetes, ${ }^{60}$ skin cancer, ${ }^{61}$ hypercholesterolaemia, ${ }^{62}$ and glucose intolerance; ${ }^{63}$ but for which Hooper et al obtained CVD event information.
The most recent review ${ }^{55}$ included no study of healthy people of both genders. The one primary, both-sex RCT available was excluded by Hooper et $a l^{24}$ for not meeting the 24 month duration criteria. The one significant finding of small benefit for CVD events, among numerous insignificant findings, thus also lacked generalisability.

Dietary fat guidelines were introduced with the ambition of reducing deaths from CHD. No meta-analysis of RCTs and/or prospective cohort studies has found any significant difference for dietary fat interventions and all-cause mortality or deaths from CHD, or associations with dietary fat and $\mathrm{CHD}$ mortality. ${ }^{15-18}$ 49-55

\section{DISCUSSION}

\section{Have there been consequences?}

The proponents of the dietary guidelines foresaw no risks and yet the coincident emergence of epidemics in obesity and diabetes suggests that this confidence may have been unjustified.

Both the $\mathrm{US}^{45}$ and $\mathrm{UK}^{46}$ documents, which introduced national dietary guidelines, acknowledged that the evidence was 
not conclusive. The UK publication referred to 'a strong consensus of opinion' (ref. 46, p. 24). Hegsted's introduction to the Dietary Goals for the USA noted "there will undoubtedly be many people who will say we have not proven our point" (ref. 45, p. 3).

Hegsted continued by asking "What are the risks associated with eating less meat, less fat, less saturated fat, less cholesterol, less sugar, less salt, and more fruits, vegetables, unsaturated fat and cereal products-especially whole grain cereals. There are none that can be identified" (ref. 45, p. 8).

Senators Percy, Schweiker and Zorinsky wrote a foreword to the second edition of the guidelines noting the "lack of consensus among nutritional scientists and other health professionals" (ref. 64, p. vii). They recommended that it be stated in bold print on the Goals and Food Selection pages "that the value of dietary change remains controversial and that science cannot at this time insure (sic) that an altered diet will improve protection from certain killer diseases such as heart disease and cancer" (ref. 64, p. ix).

The second edition of the US Dietary Goals was published at the end of $1977 .{ }^{64}$ In between the first edition ${ }^{45}$ and the second, many witnesses appeared before the committee. Deliberations were reflected in a number of comments from the second edition of the guidelines: "Some witnesses have claimed that physical harm could result from the diet modifications recommended in this report...However, after further review, the Select Committee still finds that no physical or mental harm could result from the dietary guidelines recommended for the general public"(ref. 64, p. xxxiii). The view was, therefore, that even if benefit were unproven, no harm could be done.

There are three macronutrients: carbohydrate, protein and fat. Protein is found in all foods except pure fats (oils and lard) and sucrose. ${ }^{65}$ The proportion of protein in a natural diet thus tends to remain constant at $\sim 15-20 \%$ of energy intake. ${ }^{66}$ If fat intake is reduced, as a proportion of energy intake, carbohydrate concomitantly rises. The consequences of increasing carbohydrate content in human diets had not been investigated before the dietary fat guidelines were introduced.

Until the introduction of dietary guidelines in 1977, the view of Tanner, from the Practice of Medicine, prevailed "Farinaceous and vegetable foods are fattening, and saccharine matters are especially so" (ref. 67, p. 213). In 1960, 13.3\% of US adults were obese; $44.8 \%$ were overweight. By 2007, 34.7\% of US adults were obese; $67.7 \%$ were overweight. ${ }^{68}$ In the UK, in 1972, 2.7\% of men and 2.7\% of women were obese and $23.0 \%$ of men and $13.9 \%$ of women were overweight. By 1999 , obesity rates had risen to $22.6 \%$ of men and $25.8 \%$ of women, while $49.2 \%$ of men and $36.3 \%$ of women were overweight. $^{69}$ (Health was devolved in the UK in 1999 to the regions of England, Northern Ireland, Scotland and Wales and thus UK statistics terminated).

The diabetes rate was $2.4 \%$ in 1976 in the USA. ${ }^{70}$ The introduction to the 2010 Dietary Guidelines for Americans reported that 24 million Americans, almost 11\% of the adult population, were diabetic and 78 million Americans, $35 \%$ of the adults, were pre-diabetic. ${ }^{71}$ This has recently been updated to 29 million diabetics and 86 million pre-diabetics. ${ }^{72} \mathrm{~A}$ recent review in the Lancet estimated that the lifetime risk for developing diabetes was $40.2 \%$ for American men and $39.6 \%$ for women. ${ }^{73}$ There were 800000 people with diabetes in the UK in 1980, from a population of 56 million-an incident rate of $1.42 \% .{ }^{74}$ The diabetes rate in the UK in 2015 was $6.1 \% .^{75}$ The incident rate of diabetes, both in the USA and the UK, has increased more than fourfold since the dietary fat guidelines were introduced.
The association between the introduction of the dietary fat guidelines and concomitant increases in obesity and diabetes deserves examination. A number of recent reviews have suggested a causal connection: "The replacement of saturated fats in the diet with carbohydrates, especially sugars, has resulted in increased obesity and its associated health complications" (ref. 76, p. 294). In a BMJ Editorial, cardiologist Malhotra closed with the statement: "It is time to bust the myth of the role of saturated fat in heart disease and wind back the harms of dietary advice that has contributed to obesity" (ref. 77, p. 1). In 2014, DiNicolantino questioned current dietary guidelines. Having reviewed data trends for dietary fat and obesity in the USA, he concluded: "These data provide a strong argument that the increase in the consumption of refined carbohydrates was the causative dietary factor for the diabetes and obesity epidemic in the USA" (ref. 78, p. 1). Following a Swedish systematic review of the literature, an article was published in the BMJ entitled "Swedish health advisory body says too much carbohydrate, not fat, leads to obesity". ${ }^{79}$ Feinman et al analysed US dietary intake for the period 1974-2000 and concluded: "During the epidemics of obesity and type 2 diabetes, caloric increases have been due almost entirely to increased carbohydrate" (ref. 80, p. 6).

\section{A way forward?}

It seems simple and obvious to suggest that populations should return to eating the natural, unprocessed food that was consumed before obesity and diabetes reached epidemic proportions; yet this is considered heresy by public health advisors. Clarification of the distinction between processed food and saturated fat could provide opportunity for agreement that processed food is unhealthy, while saturated fat is a natural part of most natural foods. It is worth noting that every food that contains fat contains all three fats: saturated; monounsaturated and polyunsaturated. ${ }^{65}$ The notion that saturated fat is harmful and unsaturated fat is healthful is illogical given their coexistence in foods required for human survival.

The Dietary Guidelines for Americans documented the sources of saturated fat in the American diet (figures 3-4, ref. 71, p. 26). Pizza, desserts, candy, potato chips, pasta, tortillas, burritos and tacos accounted for $32.6 \%$ of saturated fat consumed in the diets of US citizens aged 2 years and older. About $9.3 \%$ of dietary saturated fat came from sausages, frankfurters, bacon, ribs and burgers. In total, $12.8 \%$ came from chicken and mixed chicken dishes, beef and mixed beef dishes, and eggs and mixed egg dishes. A further $24.5 \%$ was unaccounted for and collated as 'all other food categories', most likely including, if not predominantly being, processed foods. The natural foods listed were cheese, milk, butter, nuts and seeds, which collectively accounted for $20.8 \%$ of saturated fat intake. It would have been ideal for unprocessed chicken, beef and eggs to have been separated from processed meals containing these ingredients. The diagram presented in the Dietary Guidelines is clear nonetheless. Processed foods account for the majority of saturated fat intake in the diets of Americans.

The UK classification is similar. The Family Food Survey (table 2.4, ref. 81, p. 18) documented sources of saturated fat in the UK diet. Bread, cakes, buns, pastries, biscuits, cereals, confectionery and other processed foods accounted for $33 \%$ of saturated fat intake. Milk, cream and cheese accounted for $24 \%$ of dietary saturated fat. Processed meat accounted for $16 \%$ of saturated fat intake, while unprocessed (carcass) meat was 5\%, fish $1 \%$ and eggs $1 \%$ of saturated fat intake. Fats and oils made up the remaining 19\% (99\% due to rounding errors). As with 
the USA, processed food accounted for the majority of the saturated fat intake in the UK.

There is opportunity for strong agreement among health professionals. If the public health message were revised to advise citizens to eat natural food and not processed food, saturated fat intake would fall accordingly, although the health benefit would most likely be the concomitant reduction in sucrose, trans fats, refined carbohydrates and other processed ingredients deleterious to human health. Human beings evolved to eat foods available from the natural environment. ${ }^{82}$ It does not seem logical to advise populations away from carcass meat, dairy produce, eggs, nuts and seeds, in the name of saturated fat, when the modern processed foods, biscuits, cakes, pizza, desserts and ready meals are more sensibly related to modern illness. ${ }^{65}$

\section{Close}

An exchange between Dr Robert Olson of St Louis University and Senator George McGovern, chair of the Dietary Committee, was recorded in July $1977 .{ }^{83}$ Olson said "I pleaded in my report and will plead again orally here for more research on the problem before we make announcements to the American public." McGovern replied "Senators don't have the luxury that the research scientist does of waiting until every last shred of evidence is in".

The evidence is now in. Indeed, the evidence was available at the time. The original problem was defined in middle-aged men. Middle-aged men were the primary focus of RCTs and epidemiological evidence at the time: secondary men for the intervention trials and largely healthy men for the cohort studies. Despite only one study finding associations, ${ }^{1}$ and many others advising caution ${ }^{21} 2328$ and despite a total lack of generalisability, guidelines were introduced for whole populations and have prevailed since.

An additional consequence of the guidelines is that, while it has been assumed that total and saturated dietary fat and dietary and serum cholesterol have been primary causes of CHD, factors of genuine concern have not been investigated as fully as they warrant.

Public health dietary fat guidelines need urgent review and revision.

\section{What are the findings?}

- Dietary recommendations were introduced in the USA (1977) and in the UK (1983) to (1) reduce overall fat consumption to $30 \%$ of total energy intake and (2) reduce saturated fat consumption to $10 \%$ of total energy intake. Four systematic reviews have been undertaken of the randomised controlled trial (RCT) and prospective cohort study evidence available to the dietary committees and that currently available. This paper presents the totality of the evidence, then and now, to show that the extant dietary fat guidelines were and are without evidence base.

- Even if the evidence had been overwhelming, the limitations of the studies were so great that the evidence could not be relied on.

- Other meta-analyses of RCTs and/or prospective cohort studies have reported 39 risk ratios between them, 35 of which were not significant. Not one of the four significant results found any relationship between dietary fat (total or saturated) and mortality.
How might this impact on clinical practice in the future?

- Public health advice on dietary fat has prevailed since 1977 I 1983 in the absence of supporting evidence. Dietary advice in both nations need re-examination.

- Dietary guidelines to restrict total fat intake to $30 \%$ concomitantly established a carbohydrate intake of $55 \%$. Diabetes and obesity have increased dramatically since; this association needs examination.

- Official listed sources of saturated fat are essentially lists of processed foods: baked goods, confectionery, desserts, snacks, and processed ready meals. A way forward in the current dietary guideline 'battle' could be agreement that processed food should be the subject of attack, not any natural fat in natural food.

Twitter Follow Zoe Harcombe at @zoeharcombe

Competing interests $\mathrm{ZH}$ receives income from writing and from two small self-employment businesses: The Harcombe Diet Co and Columbus Publishing.

Provenance and peer review Not commissioned; externally peer reviewed.

\section{REFERENCES}

1 Coronary heart disease in seven countries I. The study program and objectives. Circulation 1970;41(4 Suppl):11-8.

2 Stuckey NW. Uber die Veranderungen der kaninchen aorta unter der Wirkung reichlicher tierscher nahrung. Zentralb/ Allg Pathol Pathol Anat 1911;22:379-80.

3 Stuckey NW. Uber die Veranderungen der kaninchen-aorta bei der futterung mit verschiedenen fettsorten. Zentralb/ Allg Pathol Pathol Anat 1912;23:910-11.

4 Chalatow SS. Uber das verhalten der leber gegenuber den verschiedenen arten von Speisefett. Virchows Arch Pathol Anat Physiol Klin Med 1912;207:452-69.

5 Wesselkin NW. Uber die Ablagerung von fettartigen Stoffen in den Organen. Virchows Arch Pathol Anat Physiol Klin Med 1913;212:225-35.

6 Anitschkow N. Über die Veränderungen der Kaninchenaorta bei experimenteller Cholesterinsteatose. Beitr Pathol Anat 1913;56:379-404

7 Kon Y. Referat uber arteriosklerose. Trans Jpn Pathol Soc 1913:3:8-19.

8 Kon Y. Futterungsversuche an Saugetieren mit leberpulver und eigelb. Trans Jpn Pathol Soc 1914:4:105-12.

9 Knack AV. Uber cholesterinsklerose. Virchows Arch Pathol Anat Physiol Klin Med 1915:220:36-52.

10 Keys A, Anderson JT. The relationship of the diet to the development of atherosclerosis in man. In: National Research Council DoMS, ed. Symposium on atherosclerosis. Washington: National Academy of Sciences - National Research Council, 1954:181-96.

11 Keys A, Fidanza F, Scardi V, et al. Studies on serum cholesterol and other characteristics of clinically healthy men in Naples. Arch Int Med 1954;93:328-36.

12 Keys A. Atherosclerosis: a problem in newer public health. J Mt Sinai Hosp N Y 1953:20:118-39

13 Yerushalmy J, Hilleboe HE. Fat in the diet and mortality from heart disease; a methodologic note. N Y State J Med 1957;57:2343-54.

14 Bronte-Stewart B, Keys A, Brock JF. Serum-Cholesterol, diet and coronary heart-disease: an inter-racial survey in the Cape Peninsula. Lancet 1955;266:1103-8.

15 Harcombe Z, Baker JS, Cooper SM, et al. Evidence from randomised controlled trials did not support the introduction of dietary fat guidelines in 1977 and 1983: a systematic review and meta-analysis. Open Heart 2015;2:e000196.

16 Harcombe Z, Baker JS, Davies B. Evidence from prospective cohort studies did not support the introduction of dietary fat guidelines in 1977 and 1983: a systematic review. Br J Sports Med Published Online First: 29 Jun 2016. doi:10.1136/bjsports2016-096409

17 Harcombe Z, Baker JS, DiNicolantonio JJ, et al. Evidence from randomised controlled trials does not support current dietary fat guidelines: a systematic review and meta-analysis. Open Heart 2016;3:e000409.

18 Harcombe Z, Baker J, Davies B. Evidence from prospective cohort studies does not support current dietary fat guidelines: a systematic review and meta-analysis. Br J Sports Med Published Online First: 3 Oct 2016. doi:10.1136/bjsports-2016096550

19 Watts GF, Lewis B, Brunt JN, et al. Effects on coronary artery disease of lipid-lowering diet, or diet plus cholestyramine, in the St Thomas' Atherosclerosis Regression Study (STARS). Lancet 1992;339:563-9. 
20 Burr ML, Fehily AM, Gilbert JF, et al. Effects of changes in fat, fish, and fibre intakes on death and myocardial reinfarction: Diet and Reinfarction Trial (DART). Lancet 1989;2:757-61.

21 Research Committee. Low-fat diet in myocardial infarction: a controlled trial. Lancet 1965;2:501-4

22 Howard BV, Van Horn L, Hsia J, et al. Low-fat dietary pattern and risk of cardiovascular disease: the Women's Health Initiative Randomized Controlled Dietary Modification Trial. JAMA 2006;295:655-66.

23 Woodhill JM, Palmer AJ, Leelarthaepin B, et al. Low fat, low cholesterol diet in secondary prevention of coronary heart disease. Adv Exp Med Biol 1978;109:317-30.

24 Frantz ID Jr, Dawson EA, Ashman PL, et al. Test of effect of lipid lowering by diet on cardiovascular risk. The Minnesota Coronary Survey. Arteriosclerosis 1989;9:129-35.

25 Coronary heart disease in seven countries. Summary. Circulation 1970;41(4 Suppl): 1186-95.

26 Boniface DR, Tefft ME. Dietary fats and 16-year coronary heart disease mortality in a cohort of men and women in Great Britain. Eur J Clin Nutr 2002;56:786-92.

$27 \mathrm{Xu}$ J, Eilat-Adar S, Loria C, et al. Dietary fat intake and risk of coronary heart disease: the Strong Heart Study. Am J Clin Nutr 2006;84:894-902.

28 Rose GA, Thomson WB, Williams RT. Corn oil in treatment of ischaemic heart disease. Br Med J 1965;1:1531-3.

29 Dayton S, Pearce ML, Hashomoto S, et al. A controlled clinical trial of a diet high in unsaturated fat in preventing complications of atherosclerosis. Circulation 1969;40(1 Suppl 2):II-1-63.

30 European Medicines Agency. Repatha INN-evolocumab: summary of product characteristics. Agency EM, 2015:71.

31 Ostlund RE Jr. Phytosterols in human nutrition. Annu Rev Nutr 2002:22:533-49.

32 Weihrauch JL, Gardner JM. Sterol content of foods of plant origin. J Am Diet Assoc 1978:73:39-47.

33 Pollak OJ. Reduction of blood cholesterol in man. Circulation 1953:7:702-6.

34 Harcombe Z, Baker J. Plant sterols lower cholesterol, but increase risk for coronary heart disease. Online J Bio/ Sci 2014;14:167-9.

35 Esrey KL, Joseph L, Grover SA. Relationship between dietary intake and coronary heart disease mortality: lipid Research Clinics Prevalence Follow-Up Study. J Clin Epidemiol 1996;49:211-16.

36 Cook A, Pryer J, Shetty P. The problem of accuracy in dietary surveys. Analysis of the over 65 UK National Diet and Nutrition Survey. J Epidemiol Community Health 2000;54:611-16.

37 Kipnis V, Midthune D, Freedman L, et al. Empirical evidence of correlated biases in dietary assessment instruments and its implications. Am J Epidemio 2001:153:394-403

38 Archer E, Pavela G, Lavie CJ. The inadmissibility of what we eat in America and NHANES Dietary data in nutrition and obesity research and the scientific formulation of National Dietary Guidelines. Mayo Clin Proc 2015;90:911-26.

39 Beaton GH, Milner J, McGuire V, et al. Source of variance in 24-hour dietary recall data: implications for nutrition study design and interpretation. Carbohydrate sources, vitamins, and minerals. Am J Clin Nutr 1983:37:986-95.

40 Freedman LS, Schatzkin A, Wax Y. The impact of dietary measurement error on planning sample size required in a cohort study. Am J Epidemiol 1990;132:1185-95.

41 Keys A. Coronary heart disease in seven countries XVII. The Diet. Circulation 1970:41:1-162-83.

42 Yudkin J. Diet and coronary thrombosis: hypothesis and fact. Lancet 1957;270:155-62.

43 Hill $A B$. The environment and disease: association or causation? Proc $R$ Soc Med 1965;58:295-300.

44 Mente A, de Koning L, Shannon HS, et al. A systematic review of the evidence supporting a causal link between dietary factors and coronary heart disease. Arch Intern Med 2009;169:659-69.

45 Select Committee on Nutrition and Human Needs. Dietary goals for the United States. 1st edn. Washington: U.S. Govt. Print. Off., 1977.

46 National Advisory Committee on Nutritional Education (NACNE). A discussion paper on proposals for nutritional guidelines for health education in Britain. London: The Health Education Council, 1983.

47 Select Committee on Nutrition and Human Needs. Dietary goals for the United States, supplemental views. Washington: U.S. Govt. Print. Off., 1977.

48 Ancel Keys P. Front Cover. Time Magazine. Physiologist Ancel Keys. Time Magazine Jan 13 1961:Vol. LXXVII No.3.

49 Schwingshackl L, Hoffmann G. Dietary fatty acids in the secondary prevention of coronary heart disease: a systematic review, meta-analysis and meta-regression. BMJ Open 2014;4:e004487

50 Hooper L, Summerbell CD, Thompson R, et al. Reduced or modified dietary fat for preventing cardiovascular disease. Cochrane Database Syst Rev 2011;(7):CD002137.

51 Mozaffarian D, Micha R, Wallace $S$. Effects on coronary heart disease of increasing polyunsaturated fat in place of saturated fat: a systematic review and meta-analysis of randomized controlled trials. PLoS Med 2010;7:e1000252.
52 Siri-Tarino PW, Sun Q, Hu FB, et al. Meta-analysis of prospective cohort studies evaluating the association of saturated fat with cardiovascular disease. Am J Clin Nutr 2010;91:535-46.

53 Skeaff CM, Miller J. Dietary fat and coronary heart disease: summary of evidence from prospective cohort and randomised controlled trials. Ann Nutr Metab 2009:55:173-201.

54 Chowdhury R, Warnakula S, Kunutsor $\mathrm{S}$, et al. Association of dietary, circulating, and supplement fatty acids with coronary risk: a systematic review and meta-analysis. Ann Intern Med 2014;160:398-406.

55 Hooper L, Martin N, Abdelhamid A, et al. Reduction in saturated fat intake for cardiovascular disease. Cochrane Database Syst Rev 2015;(6):CD011737.

56 Ravnskov U, DiNicolantonio JJ, Harcombe $Z$, et al. The questionable benefits of exchanging saturated fat with polyunsaturated fat. Mayo Clin Proc 2014;89: 451-3.

57 Turpeinen O, Karvonen MJ, Pekkarinen M, et al. Dietary prevention of coronary heart disease: the Finnish Mental Hospital Study. Int J Epidemiol 1979; 8:99-118.

58 Burr ML, Ashfield-Watt PAL, Dunstan FDJ, et al. Lack of benefit of dietary advice to men with angina: results of a controlled trial. Eur J Clin Nutr 2003;57: 193-200.

59 Schmitz G, Ecker J. The opposing effects of $n-3$ and $n-6$ fatty acids. Prog Lipid Res 2008:47:147-55.

60 Houtsmuller AJ, Zahn KJ, Henkes HE. Unsaturated fats and progression of diabetic retinopathy. Doc Ophthalmol 1979:48:363-71.

61 Black HS, Herd JA, Goldberg LH, et al. Effect of a low-fat diet on the incidence of actinic keratosis. N Engl J Med 1994;330:1272-5.

62 Moy TF, Yanek LR, Raqueño JV, et al. Dietary counseling for high blood cholesterol in families at risk of coronary disease. Prev Cardiol 2001:4:158-64.

63 Ley SJ, Metcalf PA, Scragg RK, et al. Long-term effects of a reduced fat diet intervention on cardiovascular disease risk factors in individuals with glucose intolerance. Diabetes Res Clin Pract 2004;63:103-12.

64 Select Committee on Nutrition and Human Needs. Dietary goals for the United States. 2nd edn. Washington: U.S. Govt. Print. Off., 1977.

65 Harcombe Z, Baker J, Davies B. Food for thought: have we been giving the wrong dietary advice? Food Nutr Sci 2013:4:240-4.

66 Wardlaw G, Smith A. Contemporary nutrition. 7th edn. McGraw Hill, 2009.

67 Tanner TH. The practice of medicine. Philadelphia: Lindsay \& Blakiston, 1869.

68 Centers for Disease Control and Prevention. Table 71. Overweight, obesity, and healthy weight among persons 20 years of age and over, by selected characteristics: United States, selected years 1960-1962 through 2005-2008. National Center for Health Statistics, 2010

69 Wadsworth M, Kuh D, Richards M, et al. Cohort profile: the 1946 National Birth Cohort (MRC National Survey of Health and Development). Int J Epidemiol 2006:35:49-54

70 Centers for Disease Control and Prevention. Long term trends in diabetes. Translation CDoD, Centers for Disease Control and Prevention, 2014

71 Department of Health and Human Services (HHS). Dietary guidelines for Americans. Department of Health and Human Services (HHS), 2010.

72 Centers for Disease Control and Prevention. National diabetes statistics report: estimates of diabetes and its burden in the United States. USA: Department of Health and Human Services, 2014.

73 Gregg EW, Zhuo X, Cheng YJ, et al. Trends in lifetime risk and years of life lost due to diabetes in the USA, 1985-2011: a modelling study. Lancet Diabetes Endocrinol 2014;2:867-74

74 Diabetes UK. Diabetes in the UK 2004: a report from Diabetes UK October 2004. 2004:27. http://www.diabetes.org.uk/Documents/Reports/in_the_UK_2004.doc

75 Diabetes UK. Diabetes: facts and stats. 2015:22. https://www.diabetes.org.uk/ Documents/Position\%20statements/Facts\%20and\%20stats\%20June\%202015.pdf

76 Lawrence GD. Dietary fats and health: dietary recommendations in the context of scientific evidence. Adv Nutr 2013;4:294-302. [published Online First: Epub Date]

77 Malhotra A. Saturatedurated fat is not the major issue. BMJ 2013:347:f6340.

78 DiNicolantonio JJ. The cardiometabolic consequences of replacing saturated fats with carbohydrates or $\Omega-6$ polyunsaturated fats: Do the dietary guidelines have it wrong? Open Heart 2014;1:e000032.

79 Hansen A. Swedish health advisory body says too much carbohydrate, not fat, leads to obesity. BMJ 2013:347:f6873.

80 Feinman RD, Pogozelski WK, Astrup A, et al. Dietary carbohydrate restriction as the first approach in diabetes management. Critical review and evidence base. Nutrition 2015;31:1-13.

81 A National Statistics Publication. The family food survey. The Department for Environment, Food and Rural Affairs, 2010.

82 Gowlett JAJ. What actually was the Stone Age diet? J Nutr Environ Med 2003:13:143-7.

83 CBS News. Exchange between Dr Robert Olson and Senator George McGovern from the United States Senate Select Committee on Nutrition and Human Needs. Washington, 1977. 